\title{
Article \\ Off-Target-Based Design of Selective HIV-1 PROTEASE Inhibitors
}

\author{
Gabriele La Monica (D), Antonino Lauria*(D), Alessia Bono (D) and Annamaria Martorana (D) \\ Dipartimento di Scienze e Tecnologie Biologiche, Chimiche e Farmaceutiche "STEBICEF", Università degli Studi \\ di Palermo, Viale delle Scienze-Ed, 17-90128 Palermo, Italy; gabriele.lamonica01@unipa.it (G.L.M.); \\ alessia.bono01@community.unipa.it (A.B.); annamaria.martorana@unipa.it (A.M.) \\ * Correspondence: antonino.lauria@unipa.it
}

Citation: La Monica, G.; Lauria, A.; Bono, A.; Martorana, A. Off-TargetBased Design of Selective HIV-1 PROTEASE Inhibitors. Int. J. Mol. Sci. 2021, 22, 6070. https://doi.org/ $10.3390 /$ ijms 22116070

Academic Editor: Sugunadevi Sakkiah

Received: 16 May 2021

Accepted: 2 June 2021

Published: 4 June 2021

Publisher's Note: MDPI stays neutral with regard to jurisdictional claims in published maps and institutional affiliations.

Copyright: (c) 2021 by the authors. Licensee MDPI, Basel, Switzerland. This article is an open access article distributed under the terms and conditions of the Creative Commons Attribution (CC BY) license (https:/ / creativecommons.org/licenses/by/ $4.0 /)$.
Abstract: The approval of the first HIV-1 protease inhibitors (HIV-1 PRIs) marked a fundamental step in the control of AIDS, and this class of agents still represents the mainstay therapy for this illness. Despite the undisputed benefits, the necessary lifelong treatment led to numerous severe side-effects (metabolic syndrome, hepatotoxicity, diabetes, etc.). The HIV-1 PRIs are capable of interacting with "secondary" targets (off-targets) characterized by different biological activities from that of HIV-1 protease. In this scenario, the in-silico techniques undoubtedly contributed to the design of new small molecules with well-fitting selectivity against the main target, analyzing possible undesirable interactions that are already in the early stages of the research process. The present work is focused on a new mixed-hierarchical, ligand-structure-based protocol, which is centered on an on/off-target approach, to identify the new selective inhibitors of HIV-1 PR. The use of the well-established, ligand-based tools available in the DRUDIT web platform, in combination with a conventional, structure-based molecular docking process, permitted to fast screen a large database of active molecules and to select a set of structure with optimal on/off-target profiles. Therefore, the method exposed herein, could represent a reliable help in the research of new selective targeted small molecules, permitting to design new agents without undesirable interactions.

Keywords: molecular docking; molecular descriptors; ligand-structure based; DRUDIT; on/offtargets; virtual screening; HIV-1 protease; NCI database

\section{Introduction}

\subsection{Proteases: Key Enzymes for HIV Maturation}

Retroviral HIV-1 PRotease (HIV-1 PR), also called retropepsin, plays an essential role in the process of maturation of non-infectious spherical virions. Similar to other proteases, in specific proteolytic cleavage sites, HIV-1 PR processes polyproteins (especially Gag and Gag-Pol, associated with virion membrane) to yield functional individual subunits (structural proteins such as MA, CA, and NC that are involved in the stabilization of the lipidic envelope, capsid, and nucleocapsid, respectively; and enzymes such as reverse transcriptase, protease, and integrase) [1,2]. The inefficient or defective activity of the protease leads to unmatured viral particles with reduced/absent infectivity [3-5]; for this reason, HIV-1 PR has long been studied and represents, even today, a key target for AIDS therapy.

From a biomolecular point of view, HIV-1 PR is a small aspartic protease, which is formed in its active form, by two identical monomers of 99 amino acids interacting with each other at a dimer-interface, through a $\beta$-sheet structure. Each monomer folds into a compact structure of $\beta$-strands with a short $\alpha$-helix near the $C$ terminus. The pseudosymmetric active site appears to be a central cavity, equally defined at the interface of the two monomers by residues 8, 23-32, 45-56, 76, and 80-84 from both subunits; each of them exposes the highly conserved catalytic triads $\mathrm{Asp}^{25}, \mathrm{Thr}^{26}$, and Gly ${ }^{27}$, involved in the mechanism of action [1,6-12]. 
The mutational analysis of both $\mathrm{Asp}^{25}$ residues demonstrates their central role in the catalysis. The substitutions with Asn, Thr, or Ala lead to an enzyme without any proteolytic activity $[5,9,13-15]$. These two key residues are planar and interact strictly with substrates and inhibitors [16]. During the catalytic mechanism, these residues coordinate a molecule of water to hydrolyze the specific peptide bond, with the formation of an oxyanion tetrahedral intermediate (general acid-base catalysis) [15,17-19].

A flexible glycine-rich "flap" region (residues 44-57) consisting of two $\beta$-hairpins, covers the active cleft, and cooperates in substrate recognition and stabilization and in the regulation of the catalytic activity. Indeed, depending on the binding of a substrate or of a small molecule, this region undergoes conformational changes, assuming an open, a semi-open, or a close conformation [20-22]. The endogenous substrates present at least seven amino acids and a cleavable peptide bond located between the fourth and fifth residues, starting from the $\mathrm{N}$ terminus [23].

\subsection{Inhibitors of HIV Protease: Main Features and off-Target Effects}

The introduction in clinical practice of saquinavir (1995) (Figure 1), the first HIV-1 PRI (HIV-1 PRotease Inhibitor), represented an important step for AIDS therapy. Indeed, even today, the combination therapy of HIV-1 PRI and reverse transcriptase inhibitors (HAART, highly active antiretroviral therapy) is the standard pharmaceutical approach [24,25].

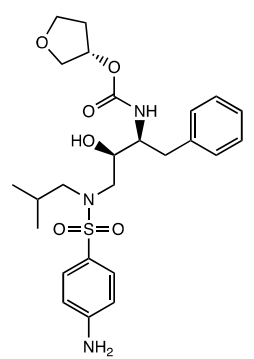

amprenavir

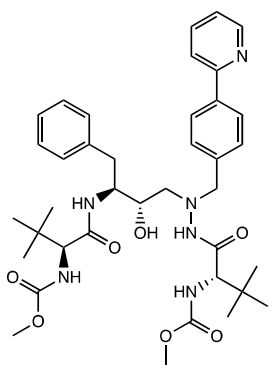

atazanavir

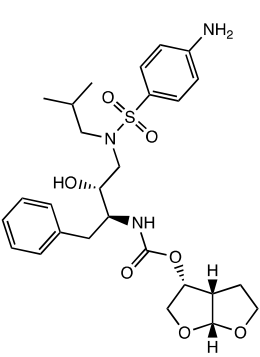

darunavir

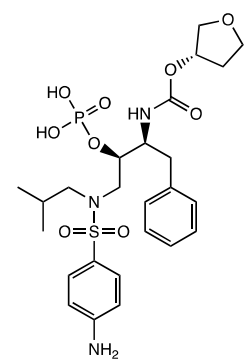

fosamprenavir

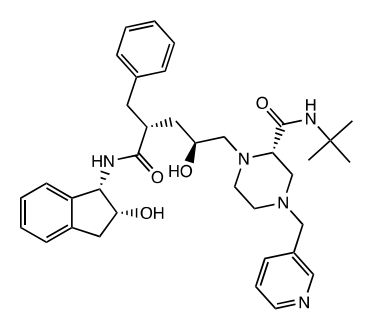

indinavir

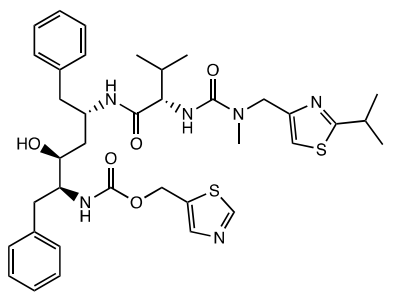

ritonavir

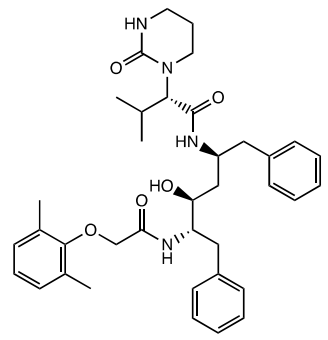

lopinavir

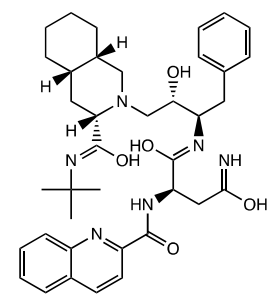

saquinavir

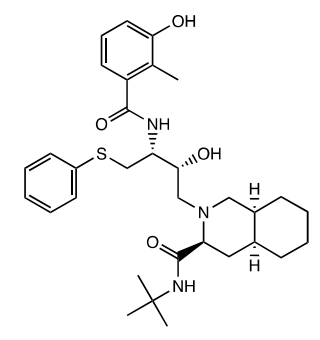

nelfinavir

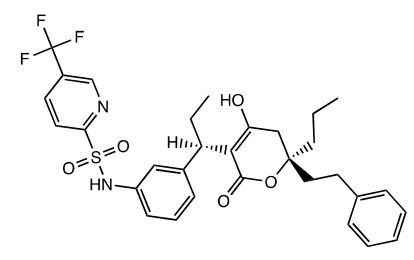

tipranavir

Figure 1. Chemical structures of the HIV-1 PR inhibitors approved by the FDA since 1995.

All FDA-approved HIV-1 PRIs (saquinavir and amprenavir are no longer marketed; ritonavir, fosamprenavir, lopinavir, indinavir, atazanavir, nelfinavir, tipranavir and darunavir used for clinical treatment, Figure 1) are competitive inhibitors at the catalytic active site, binding the protease in its closed conformation (flaps folded over the active site, as in the 
crystal structure of HIV-1 protease in complex with darunavir, PDB id: 2IEN, Figure 2). Through this mechanism of action, the inhibitors maintain the enzyme in a locked-down state, hindering access to natural substrates $[24,26,27]$.

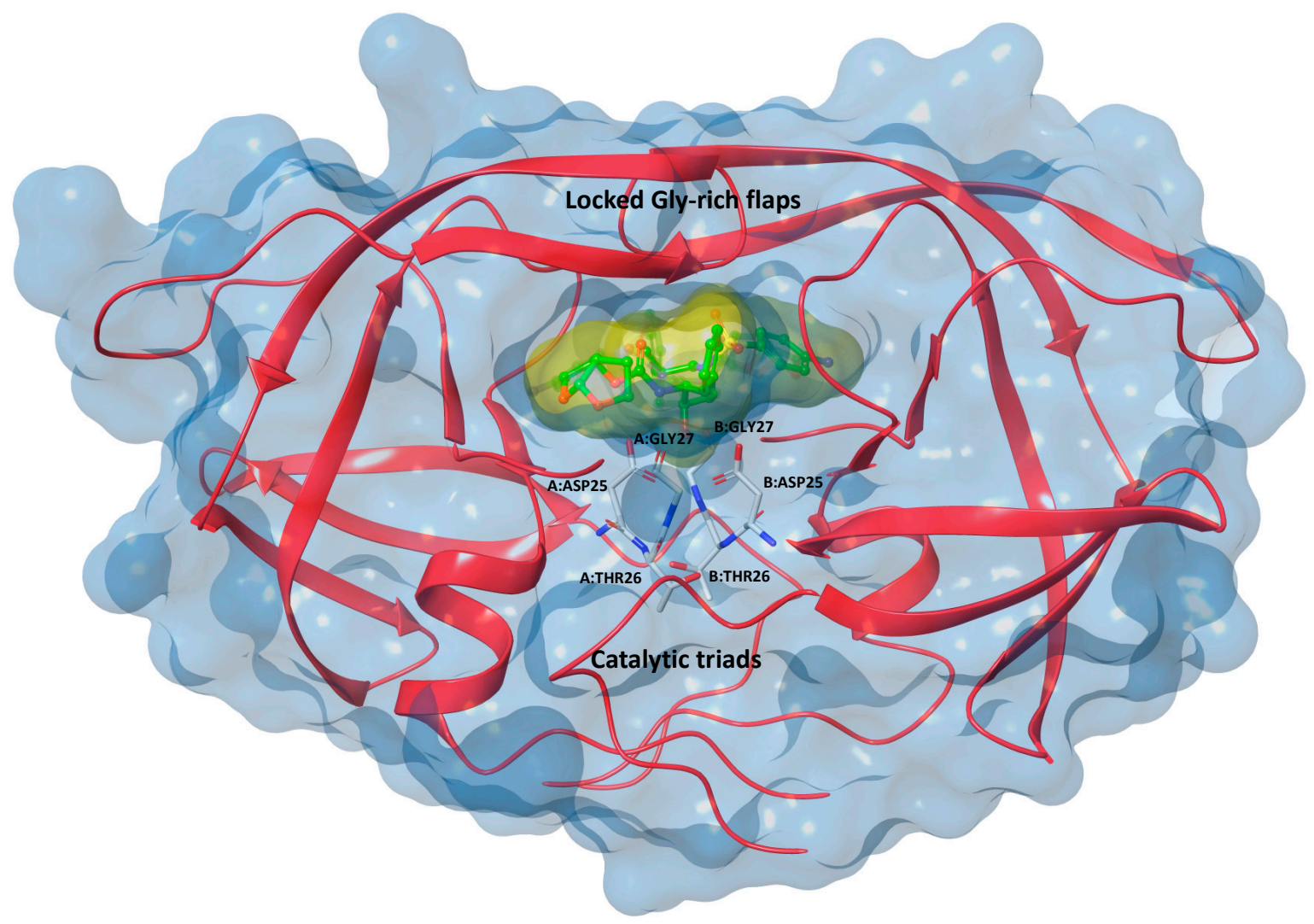

Figure 2. 3D structure of HIV-1 PR in complex with darunavir (PDB id: 2IEN), with the two catalytic triads (Asp ${ }^{25}$, Thr ${ }^{26}$, and $\mathrm{Gly}^{27}$ ) highlighted [26].

Generally, from a structural point of view, the central moieties of HIV-1 PRIs present a set of non-hydrolyzable hydrocarburic chains (hydroxyethylene, hydroxyethyl amine, and hydroxyethylenamino-sulfonamide), which mimic the tetrahedral-hydroxy catalytic intermediates of the peptide substrates and form favorable electrostatic interactions with the two pivotal $\mathrm{Asp}^{25}$ amino acids [15,28].

Besides the increasing drug-resistance to conventional therapy [10,11,29], another important problem in the treatment of HIV / AIDS patients with HIV-1 PRIs is the variety of the targets, which, as "minor" targets, could be activated after HIV-1 PRIs administrations [30]. Drug promiscuity represents the molecular basis for polypharmacology [31], that is, the capability of a compound to interact with multiple targets. In some multifactorial diseases, such as cancer or Alzheimer, the interaction with multiple interconnected targets can be advantageous. In other cases, this promiscuity leads to interaction with not desired/harmful targets (called off-targets or anti-targets) that are frequently responsible for mediating side effects [32].

The harmful promiscuity of HIV-1 PRIs is well-known. Several studies demonstrated the capability of many PRIs to inhibit not only the primary target, but also other ones involved in the regulation of glucose and lipids homeostasis, as well as cell proliferation and survival [30,33-36]. Indeed, from a biomolecular point of view, this evidence is reported in the literature and describes the capability of HIV-1 PRIs to inhibit the Akt, EGFR, and IGF1-R pathways involved in the regulation of metabolic processes, and also investigated in anticancer therapy [35-42]. 
The interactions of HIV-1 PRIs with the off-targets are in part the cause of the oftenunbearable side effects-dyslipidemia, hepatotoxicity, insulin resistance, diabetes, and lipodystrophy/lipoatrophy, in addition to cardiovascular and cerebrovascular diseases. The off-target effects represent an important drawback, especially in the light of lifelong treatment for patients infected by HIV. Indeed, despite the undisputed benefits, these side effects negatively affect their quality of life $[1,34,37,43,44]$.

According to Lv et al., the use of new scaffolds or lead compounds in the design of HIV protease inhibitors might lead to alternative binding patterns, becoming a possible solution to the reduction of drug side effects of the FDA-approved PRIs [30]. Therefore, the prediction of off-target interactions, through polypharmacological computational approaches, already in the early stages of drug discovery and development process, could strongly help pharmaceutical research, saving time and resources, and reducing the risk of failure [32,45-47]. In this regard, Xie et al. developed a computational bioinformatics approach that allowed us to better understand the side effects of nelfinavir, through the analysis of its putative off-targets [35,48].

Therefore, in this work, an innovative on/off-target based in silico protocol is reported, with the aim of identifying new and more selective HIV-1 PRIs. Particular attention has been paid to the analysis of the low affinity of the studied HIV-1 PRIs against the off-targets responsible for the side effects, in patients treated with approved PRIs. The protocol develops in two steps (ligand- and structure-based). The use of the ligand-based method in the first step allows us to perform fast and reliable virtual screenings, without the need for high-performance hardware and software.

\section{Results}

\subsection{In Silico Ligand-Based Approach in the Identification of Selective HIV-1 PR Inhibitors}

In the first step of the protocol (Figure 3), the well-established ligand-based computational approaches centered on molecular descriptors, recently implemented in the web-service DRUDIT [49], was applied. In particular, it has been employed the BIOTARGET finder tool in an on/off-target mode (explained in the Materials and Methods section) [49].

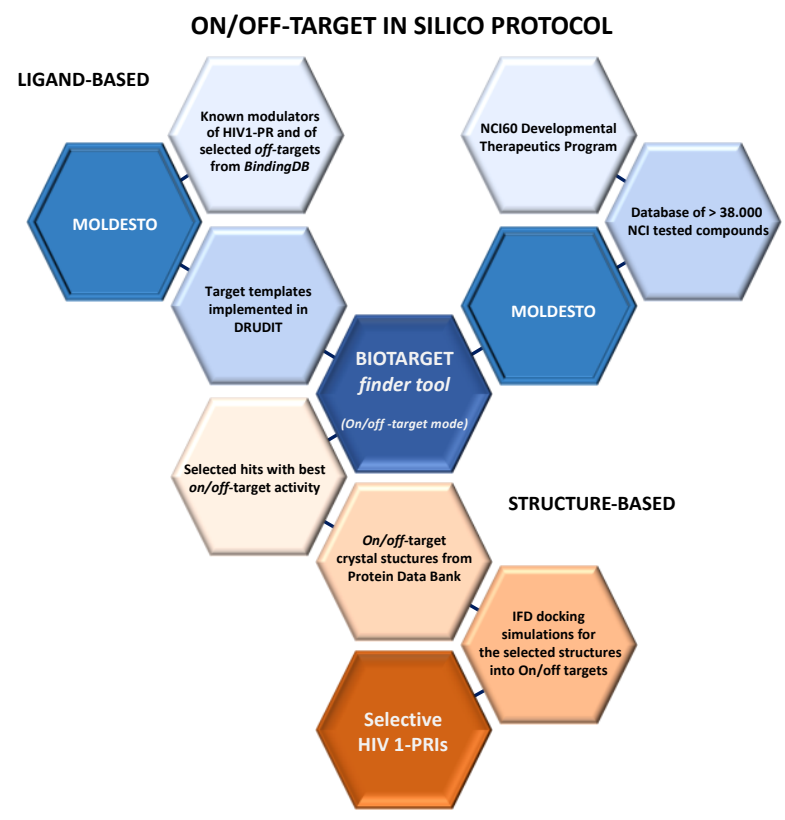

Figure 3. Workflow of the in silico mixed structure-ligand on/off-target approach proposed for the identification of new HIV-1 PR inhibitors.

For the building of the on/off-target templates, four ligand datasets were selectedone included the known modulators of the on-target (HIV-1 PR) and the other constituted 
the known inhibitors of the well-known off-targets (AKT, EGFR, and IGF1R). The BindingDB, a web-accessible database where the $\mathrm{K}_{\mathrm{i}}, \mathrm{K}_{\mathrm{d}}, \mathrm{IC}_{50}$, and $\mathrm{EC}_{50}$ values for thousand active molecules against the corresponding known target/s are available [50], was used as a reliable source for the modulators. These structures databases were subjected to a laborious cleaning work, with the aim of deleting duplicates and selecting only the most active compounds, fixing the $\mathrm{IC}_{50}$ cut-off at $1 \mu \mathrm{M}$. Then, the selected structures were employed to build the molecular descriptor-based target templates, according to the procedure reported in the literature $[49,51]$. In brief, the four ligand datasets were processed by MOLDESTO (MOLecular DEScriptors TOols, a proprietary software implemented in DRUDIT), which can calculate more than 1400 molecular descriptors (3D, 2D, and 1D) for the input structures. The output matrices (structures versus molecular descriptors), one for each target (HIV-1 PR, AKT, EGFR, and IGF1R), were converted into a sequence of a pair of values for each molecular descriptor-mean and standard deviation. The four sequences of these couple of values represented the ligand-based target templates.

Once the targets templates have been built and integrated in DRUDIT, the second step of the ligand-based study was focused on the virtual screening of a large ligand database, by means of the BIOTARGET finder tool available in DRUDIT, applying the on/off-target task. The aim of this part of the protocol was to filter a large database of structures through the templates, in order to select new compounds as potential selective HIV-1 PRIs, with low affinity against the putative off-targets responsible for mediating the side-effects, in patients treated with the approved HIV-1 PRIs.

The National Cancer Institute (NCI) molecular databank, constituted by thousands of compounds tested in the National Cancer Institute anticancer screening program (NCI60), was selected as a large ligand database to be screened [52,53]. Indeed, from a polypharmacological point of view, old, or unsuccessful lead compounds/drugs could be repurposed for new biological targets that are different from those for which they were developed; in silico approaches are also quite suitable for this purpose [31,54].

Therefore, more than 38,000 structures were submitted to the DRUDIT templates calculation. The analysis of the output matrix (Supplementary Material S1) allowed us to select 330 compounds, with Drudit Affinity Scores (DAS) higher than 0.7, against the on-target HIV-1 PR. Then, these selected structures (330) were further screened against the off-target receptors (EGFR, IGF1R, and ALK), in order to classify those with the best on/off-target balance, by applying the formula:

$$
\text { On } / \text { off target score }=\frac{D A S_{H I V-1 P R}}{D A S_{\chi}}
$$

where $D A S_{H I V-1 ~ P R}$ is the score for the HIV-1 PR; $D A S \chi$ is $D A S_{E G F R} \times D A S_{I G F 1 R} \times D A S_{A L K}$.

The selected chemical structures were ranked according to the following criterion-the higher on/off-target score value was the result of a higher $D A S_{H I V-1}$ PR, with a higher affinity for the on-target HIV-1 PR, and a lower $D A S_{E G F R}, D A S_{I G F 1 R}$, and $D A S_{A L K}$ for the off-targets (Supplementary Material S1). In view of this, the first twenty best ranked structures were selected to conduct further analysis.

Moreover, to better evaluate the rankings of the selected NCI structures, the FDAapproved HIV-1 PR inhibitors (Figure 1) were also screened; the overall results are reported in Table 1. By observing the results, it emerged that 5 out of 10 approved HIV-1 PRI (ritonavir, darunavir, indinavir, nelfinavir, amprenavir) reported an on/off-target score lower than the selected NCI structures. Among all, attention should be paid to nelfinavir, the second-last ranked structure, which reported an on/off-target score of 13,575, which was much lower than the average value of the structures selected by the protocol $(23,612)$. This was probably due to its non-negligible EGFR, IGF1R, and ALK inhibition activities that is extensively documented in the literature, explaining the metabolic and anticancer properties of this molecule [55], which, in this context, could be described to be a sideeffect of HIV therapy. As expected, the lower on/off-target score reflects the evidence of considerable activity on the off-targets-EGFR, IGF1R, and ALK. 
Table 1. DAS data and the on/off-target scores for the twenty top-scored structures and the 10 FDA-approved HIV-1 PR inhibitors.

\begin{tabular}{|c|c|c|c|c|c|c|}
\hline Cpd * & $D A S_{H I V-1} P R$ & $D A S_{A L K}$ & $D A S_{E G F R}$ & $D A S_{I G F 1 R}$ & $D A S \chi$ & On/Off-Target Score \\
\hline atazanavir & 0,624 & 0,272 & 0,304 & 0,246 & 0,02034 & 30,677 \\
\hline 669704 & 0,742 & 0,280 & 0,314 & 0,302 & 0,02655 & 27,945 \\
\hline 713591 & 0,700 & 0,288 & 0,312 & 0,280 & 0,02516 & 27,822 \\
\hline 669814 & 0,828 & 0,286 & 0,360 & 0,316 & 0,03254 & 25,449 \\
\hline 672457 & 0,856 & 0,294 & 0,344 & 0,334 & 0,03378 & 25,341 \\
\hline 720458 & 0,740 & 0,282 & 0,352 & 0,296 & 0,02938 & 25,185 \\
\hline 716698 & 0,842 & 0,288 & 0,352 & 0,330 & 0,03345 & 25,169 \\
\hline lopinavir & 0,816 & 0,332 & 0,332 & 0,316 & 0,03483 & 23,428 \\
\hline 694866 & 0,736 & 0,284 & 0,346 & 0,322 & 0,03164 & 23,261 \\
\hline 670360 & 0,852 & 0,314 & 0,358 & 0,326 & 0,03665 & 23,249 \\
\hline saquinavir & 0,802 & 0,304 & 0,364 & 0,312 & 0,03452 & 23,230 \\
\hline 716693 & 0,824 & 0,306 & 0,352 & 0,330 & 0,03554 & 23,182 \\
\hline 672446 & 0,770 & 0,290 & 0,342 & 0,336 & 0,03332 & 23,106 \\
\hline 716688 & 0,764 & 0,312 & 0,348 & 0,306 & 0,03322 & 22,995 \\
\hline 679680 & 0,872 & 0,316 & 0,362 & 0,334 & 0,03821 & 22,823 \\
\hline 713587 & 0,734 & 0,326 & 0,310 & 0,322 & 0,03254 & 22,556 \\
\hline 716697 & 0,802 & 0,324 & 0,350 & 0,314 & 0,03561 & 22,523 \\
\hline 668429 & 0,786 & 0,274 & 0,362 & 0,354 & 0,03511 & 22,385 \\
\hline 669663 & 0,754 & 0,292 & 0,358 & 0,324 & 0,03387 & 22,262 \\
\hline tipranavir & 0,616 & 0,294 & 0,304 & 0,312 & 0,02789 & 22,090 \\
\hline fosamprenavir & 0,694 & 0,290 & 0,312 & 0,348 & 0,03149 & 22,041 \\
\hline 688351 & 0,806 & 0,304 & 0,342 & 0,352 & 0,0366 & 22,024 \\
\hline 717708 & 0,714 & 0,310 & 0,340 & 0,312 & 0,03288 & 21,712 \\
\hline 716694 & 0,816 & 0,316 & 0,372 & 0,320 & 0,03762 & 21,693 \\
\hline 710835 & 0,772 & 0,306 & 0,344 & 0,340 & 0,03579 & 21,570 \\
\hline ritonavir & 0,802 & 0,326 & 0,344 & 0,342 & 0,03835 & 20,911 \\
\hline darunavir & 0,756 & 0,338 & 0,336 & 0,388 & 0,04406 & 17,157 \\
\hline indinavir & 0,822 & 0,372 & 0,368 & 0,362 & 0,04956 & 16,587 \\
\hline nelfinavir & 0,908 & 0,404 & 0,416 & 0,398 & 0,06689 & 13,575 \\
\hline amprenavir & 0,738 & 0,412 & 0,374 & 0,492 & 0,07581 & 9735 \\
\hline
\end{tabular}

* in bold, the FDA-approved HIV-1 PRI are highlighted.

On the other hand, the other FDA-approved HIV-1 PRI were ranked within the NCI compounds; however, three of these, atazanavir, tipranavir, and fosamprenavir, obtained a DAS HIV-1 PR lower than the cut-off 0.7 , according to the proposed model, thus they could be excluded, according to the analysis. Thus, excluding saquinavir, which is no longer marketed, only lopinavir obtained a DAS $\mathrm{HIV}_{-1}$ and an on/off target score comparable to the selected NCI structures.

In the light of these results, we decided to further investigate the inhibition effects of the twenty best-scored NCI molecules, with detailed structure-based studies.

In Figure 4, the twenty selected structures were reported from the analysis of their chemical structures. Most of these compounds presents a peptidomimetic and carbamic moieties, such as several already approved HIV-1 PR inhibitors. 

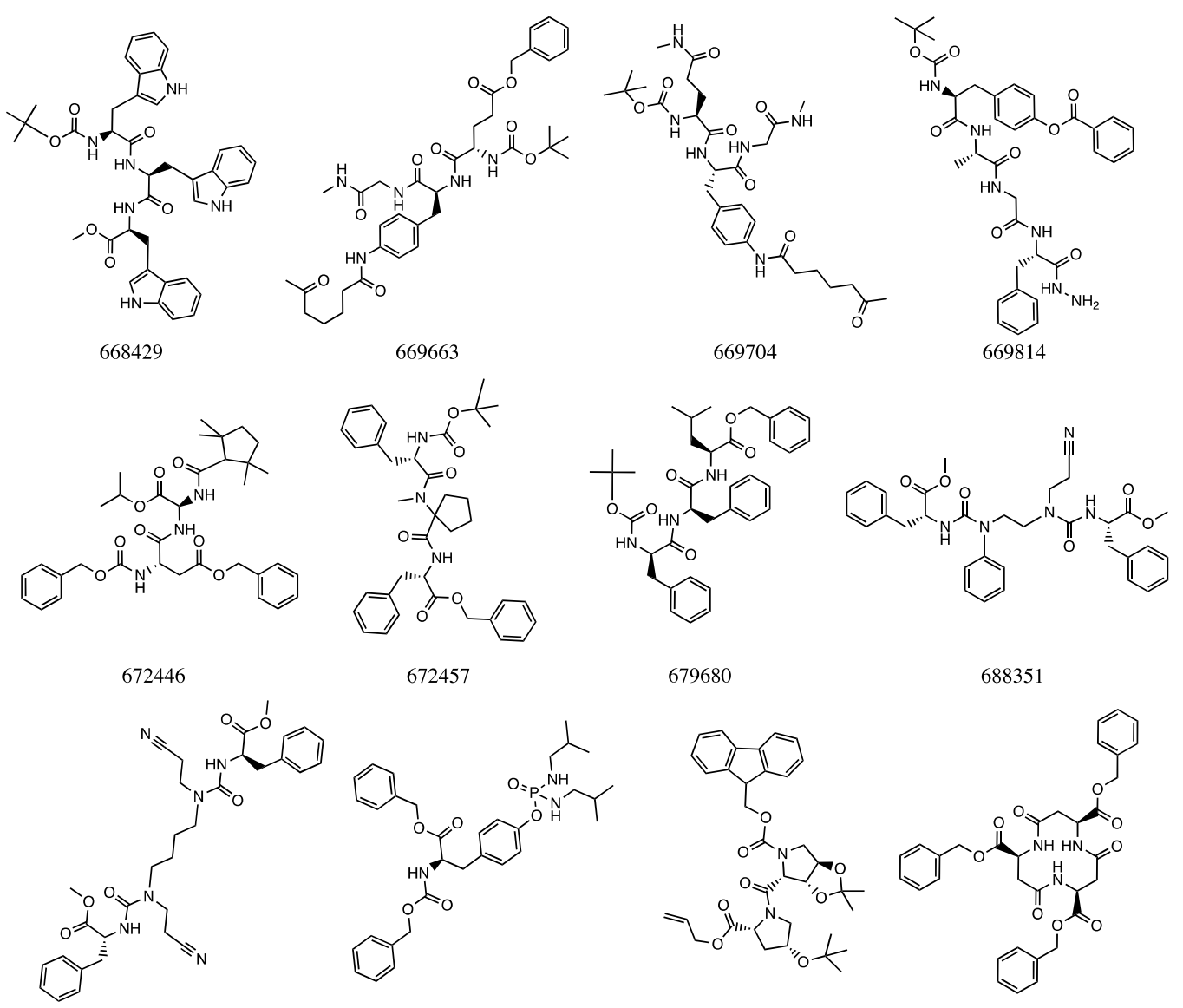

672457

679680

688351
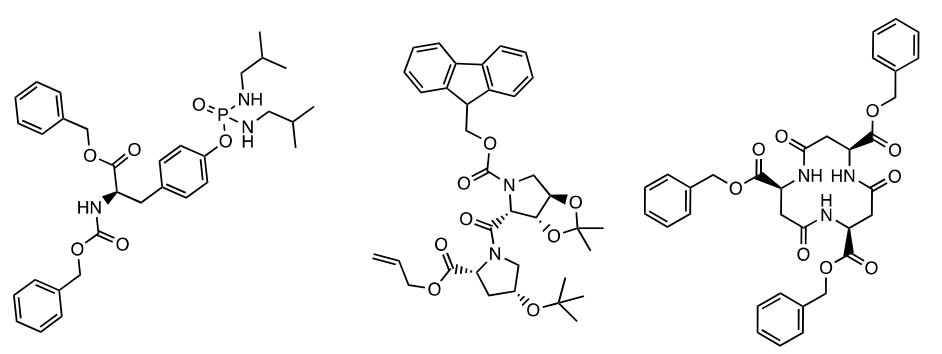

694866

710835

713587

713591

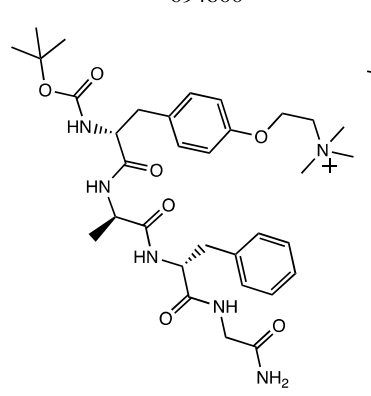

716688

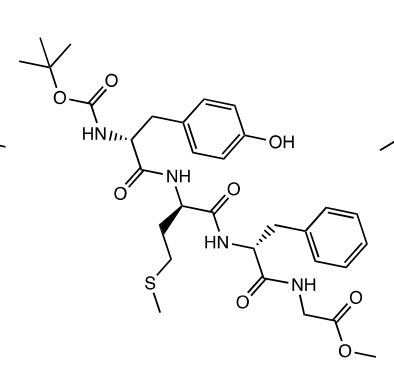

716693

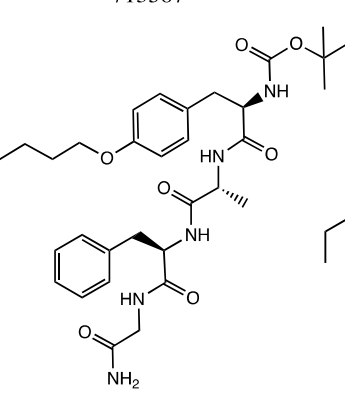

716694

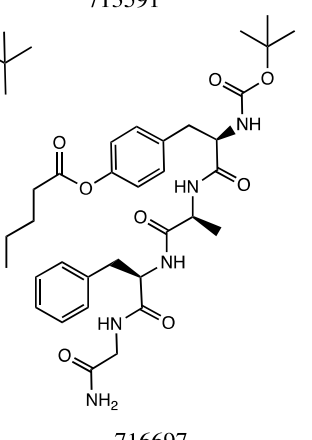

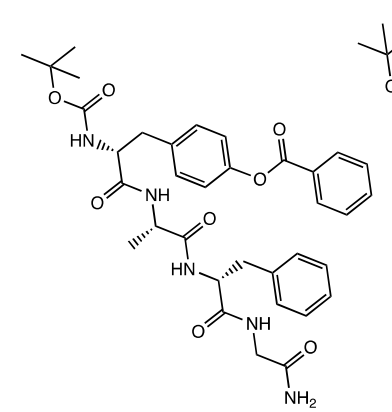

716698

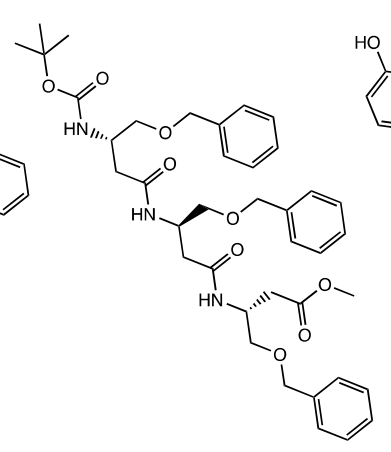

717708

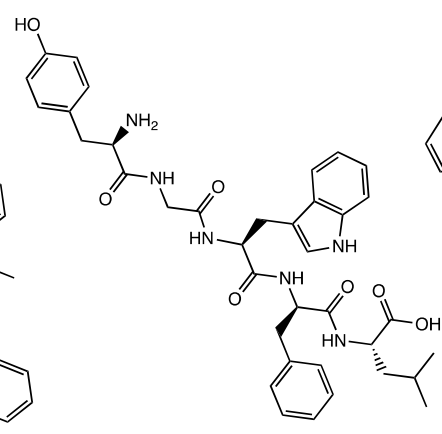

720458

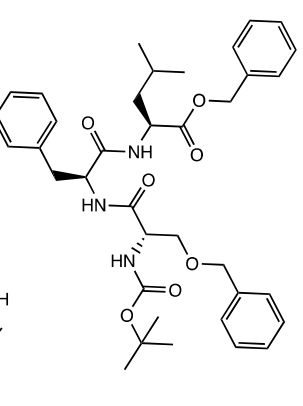

670360

Figure 4. Chemical structures of the top-scored NCI compounds obtained by the ligand-based analysis (the number reported below each structure represents the NSC number in the NCI database). 


\subsection{In Silico Structure-Based: Molecular Docking for the Best-Scored Structures}

Hybrid and hierarchical virtual screenings-composed of both sequential ligand and structure-based methods-were demonstrated to be reliable approaches in small molecule drug discovery [56]. In the second part of the protocol (Figure 3), Induced Fit Docking (IFD) simulations were processed both in on-target (HIV-1 PR, PDB id: 1HVR [57]) and off-target crystal structures (PDB id 6MX8 [58], 3W2S [59], and 5FXS [60] for ALK, EGFR, and IGF1R, respectively) selected from the Protein Data Bank [61]. The structure-based studies aimed to confirm the DRUDIT predictions and select the molecules that emerged as the most interesting (with the best on/off-target activity).

The IFD scores were analyzed and processed as follows. For each structure, the difference between the on-target docking score and the off-target docking scores was calculated. Then, the average value $(\mathrm{Y})$ of these was calculated and we decided to consider only those structure with absolute $\mathrm{Y}$ value greater than 3.5 units (implying more favorable interactions of the ligand with the on-target instead of with the off-targets, see Supplementary Material S2). In Table 2, the docking outputs were reported for the six structures beyond the cut-off of 3.5. From the on-target point-of-view, all selected NCI molecules showed a higher IFD score against the HIV-1 PR, as compared to the co-crystallized ligand, confirming a good-fit in the catalytic binding site and improved selective interactions with the HIV-1 PR. Regarding the off-target affinity, in general, the majority of the studied molecules presented lower docking/IFD scores against the off-targets, as compared to the corresponding co-crystallized ligands, suggesting a lower affinity in accordance with the DRUDIT ligand-based results.

Table 2. Docking and IFD scores of the structures that emerged from the structure-based studies, with the best on/off-target activity balance.

\begin{tabular}{|c|c|c|c|c|c|c|c|c|}
\hline \multirow[b]{2}{*}{ Structures * } & \multicolumn{2}{|c|}{ 1HVR (HIV-1 PR) } & \multicolumn{2}{|c|}{ 6MX8 (ALK) } & \multicolumn{2}{|c|}{ 3W2S (EGFR) } & \multicolumn{2}{|c|}{ 5FXS (IGF1-R) } \\
\hline & $\begin{array}{l}\text { Docking } \\
\text { Score }\end{array}$ & IFD Score & $\begin{array}{l}\text { Docking } \\
\text { Score }\end{array}$ & IFD Score & $\begin{array}{l}\text { Docking } \\
\text { Score }\end{array}$ & IFD Score & $\begin{array}{l}\text { Docking } \\
\text { Score }\end{array}$ & IFD Score \\
\hline 672457 & $-13,243$ & $-430,376$ & -7201 & $-605,292$ & $-12,100$ & -6754 & -5580 & $-383,639$ \\
\hline 716697 & $-15,061$ & $-439,048$ & $-10,402$ & $-615,334$ & $-10,134$ & $-679,858$ & $-10,843$ & $-395,718$ \\
\hline 669704 & $-13,491$ & $-438,606$ & -8894 & $-614,762$ & $-10,387$ & $-680,854$ & -8810 & $-393,550$ \\
\hline 688351 & $-12,472$ & $-431,583$ & -7793 & $-608,720$ & -9690 & $-673,572$ & -7832 & $-387,064$ \\
\hline 713587 & $-12,140$ & $-430,773$ & -7369 & $-606,621$ & -9403 & $-675,306$ & -7750 & $-386,826$ \\
\hline 717708 & $-13,491$ & $-434,575$ & -9435 & $-610,702$ & $-11,361$ & $-678,017$ & -8512 & $-386,593$ \\
\hline Co-crystallized ligands & $-14,942$ & $-430,230$ & -9205 & $-612,33$ & $-11,494$ & $-678,360$ & $-11,308$ & $-394,020$ \\
\hline
\end{tabular}

* in bold, the structures with best on/off-target activity in both ligand and structure-based analysis are reported.

The matching of the IFD results with those obtained by the DRUDIT ligand-based analysis highlights the NSC672457 and NSC669704 molecules as the most promising HIV-1 PRI. Corresponding to the first and the fourth structures in the DRUDIT ranking output file, these two compounds exhibited the best IFD on-target scores against HIV-1 PR and the lower IFD off-target scores against ALK, EGFR, and IGF1R.

In this light, the binding mode and the ligand-protein interactions of the best-docked pose of NSC672457 and NSC669704 into HIV-1 PR catalytic binding site were further analyzed.

As depicted in Figure 5, both selected molecules bind to the HIV-1 PR catalytic domain in an extended conformation, in accordance with the binding mode generally reported in the literature for other protease inhibitors [29]. Furthermore, NSC672457 and NSC669704 compounds interact with pivotal amino acids in the proteolytic active site with $\mathrm{ASPs}^{25}, \mathrm{ASPs}^{29}$, and $\mathrm{ASPs}^{30}$. H-bonds with $\mathrm{Ile}^{50}$, Gly ${ }^{48}$, and $\mathrm{Gly}^{49}$, within the two $\beta$-hairpins, could contribute to reinforcing the inhibition effect by locking the flaps (highlighted as red ribbons) in a closed conformation and hindering the entrance of the natural peptide substrates. 

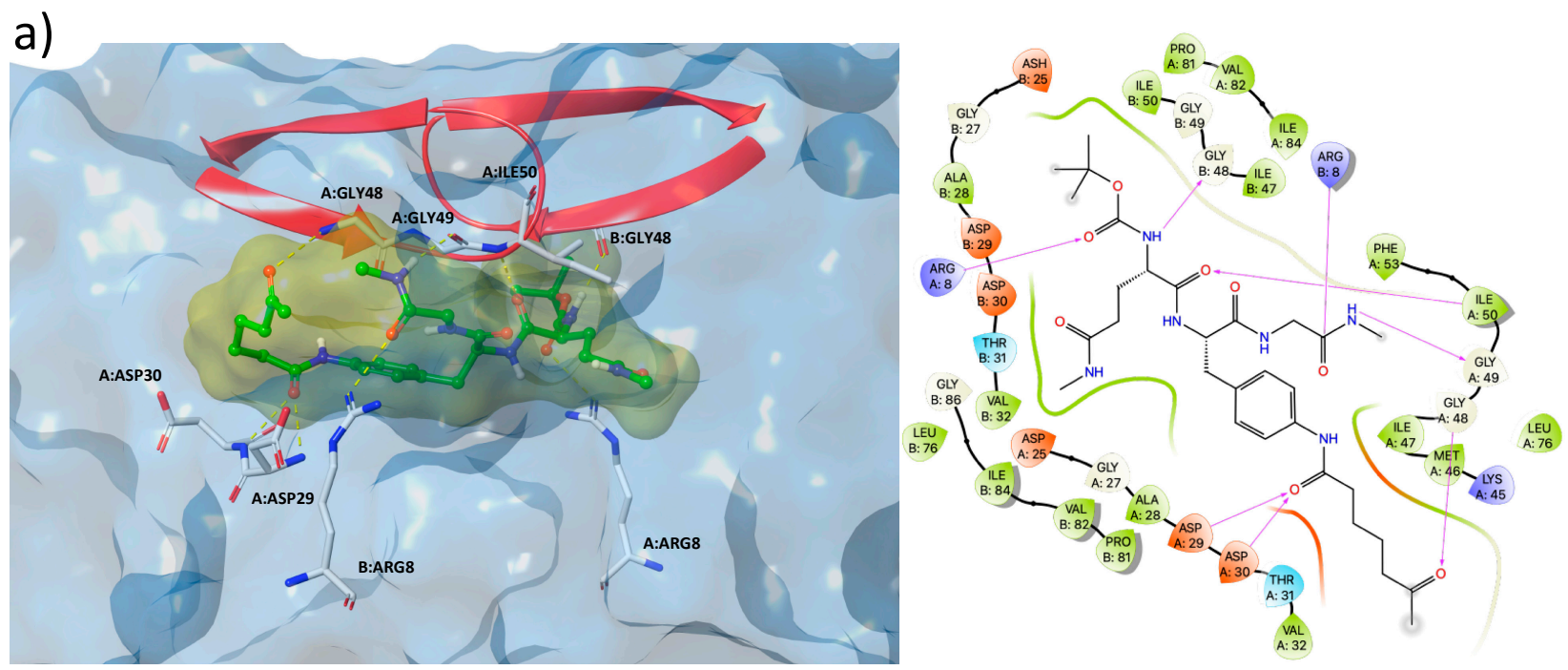

b)
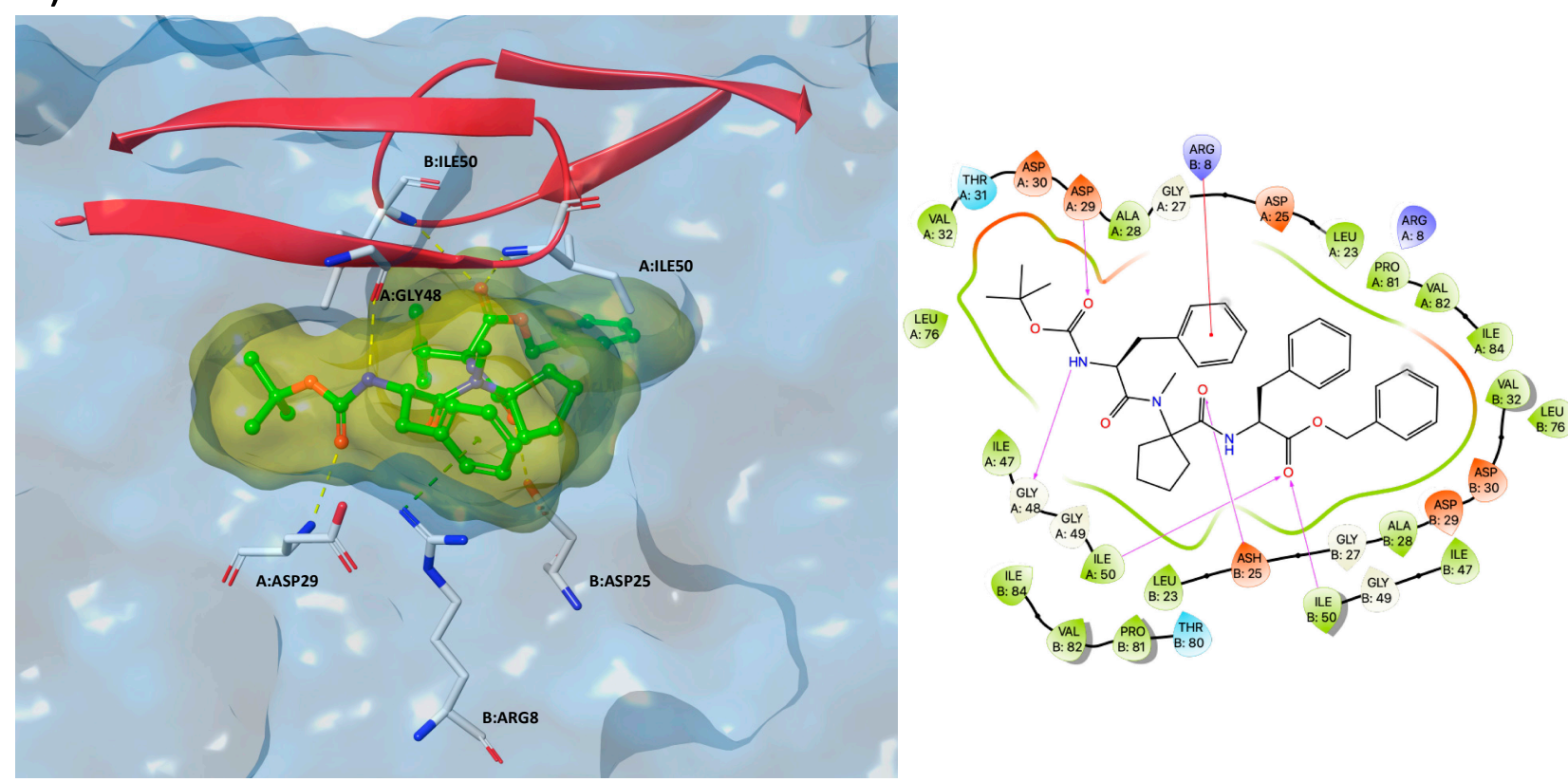

Figure 5. 3D binding modes (left) and amino acids maps (right) of the best docked pose of NSC669704 (a) and NSC672457 (b), bound to the catalytic domain of HIV-1 PR (PDB id: 1HVR).

Interestingly, NSC669704 appears for the first time in a virtual screening as putative HIV-1 PRI, while NSC672457 has been identified as a possible HIV-1 PRI, through a hierarchical virtual screening [62]. This reinforces the idea that the integration of our ligand-based tools with conventional structure-based techniques represents a valid and reliable method to screen a wide library of compounds in the targeted drug discovery field.

\section{Materials and Methods}

\subsection{Ligand-Based Studies}

The selection of suitable HIV-1 PR inhibitors was performed through the BIOTARGET finder on/off module, available in the DRugs Discovery Tools (DRUDIT) web-service (www.drudit.com) (accessed on 1 May 2021) [49]. The tool allowed analysis of the binding affinity of the candidate molecules versus a chosen biological on-target, also taking into account the correspondence to the related off-targets.

In detail, as a first step, it was necessary to build the DRUDIT templates of the biological targets of interest (on-target-HIV-1 PR; off-targets-AKT, EGFR, and IGF1R), using 
a set of well-known selective inhibitors as the reference compounds. Therefore, from the Binding DataBase [50], a wide cluster of molecules were downloaded and further filtered, by applying a cut-off of $1 \mu \mathrm{M}$ to their $\mathrm{IC}_{50}$ values. The selected structures were uploaded to the web-server DRUDIT and processed by the MOLecular DEScriptor TOol (MOLDESTO), which can deal with more than one thousand and four hundred molecular descriptors.

MOLDESTO can read common molecule file formats, such as SMILES, SDF, Inchi, $\mathrm{Mdl}$, and Mol2, to optimize structures, and is provided with a caching system to boost the calculation speed of previously submitted structures. Input structures can be drawn in the web application or uploaded to the server as external files. In either case, the structures were optimized by MOPAC before being processed by MOLDESTO. The consequent output files allowed us to obtain the expected DRUDIT biotarget templates of HIV-1 PR, AKT, EGFR, and IGF1R, which are necessary for the on/off-target screening, and in this regard, added to the list of the biological targets already available in the DRUDIT platform.

In the second step of the work, the NCI database, characterized by well-known antiproliferative data, was screened and chosen as a molecule source, to be uploaded to DRUDIT. In this phase of the workflow, the BIOTARGET finder Tool (including the new biological templates of HIV-1 PR, AKT, EGFR, and IGF1R) was selected, using the default parameters, at first, and then further analyzing the output files by ticking the on/off option.

\subsection{Structure-Based Studies}

The ligands and protein-ligand complexes used for the in silico studies were prepared as follows.

\subsubsection{Ligand Preparation}

The default setting of the LigPrep tool implemented in Schrödinger's software (version 2017-1) was used to prepare the ligands [63]. All possible tautomers and a combination of stereoisomers were generated for a $\mathrm{pH}$ of $7.0 \pm 0.4$, using the Epik ionization method [64]. Energy minimization was subsequently carried out using the integrated OPLS 2005 force field [65].

\subsubsection{Protein Preparation}

The high-resolution crystal structure of HIV-1 PR, (PDB id: 1HVR [57]) and off-target crystal structures of ALK (PDB id 6MX8 [58]), EGFR (3W2S [59]), and IGF1R (5FXS [60]) were downloaded from the Protein Databank $[61,66]$. The Protein Preparation Wizard of the Schrödinger software was subsequently employed for further preparations of the protein structures using the default setting [67]. Bond orders were assigned and hydrogen atoms were added, as well as protonation of the heteroatom states were carried out using the Epik-tool (with the $\mathrm{pH}$ set at biologically relevant values, i.e., at $7.0 \pm 0.4$ ). The H-bond network was then optimized. The structure was finally subjected to a restrained energy minimization step (RMSD of the atom displacement for terminating the minimization was $0.3 \AA$ A), using the Optimized Potentials for Liquid Simulations (OPLS) 2005 force field [65].

\subsubsection{Docking Validation}

Molecular Docking studies were performed by the Glide program [68-70]. The receptor grids preparation was carried out by assigning the original ligands as the centroid of the grid box. The generated 3D conformers were docked into the receptor model using the Standard Precision (SP) mode as the scoring function. A total of 5 poses per ligand conformer were included in the post-docking minimization step, and a maximum of 2 docking poses were generated for each ligand conformer. The proposed docking procedure was able to re-dock the original ligands within the receptor-binding pockets with RMSD $<0.51 \AA$.

\subsubsection{Induced Fit Docking}

Induced fit docking simulation was performed using the IFD application [71,72] available in the Schrödinger software suite [73], which was demonstrated to be an accurate 
and robust method to account for both ligand and receptor flexibility [74]. The IFD protocol was carried out as follows $[75,76]$ — the ligands were docked into the rigid receptor models with scaled-down van der Waals (vdW) radii. The Glide Extra Precision (XP) mode [68-70] was used for the docking, and 20 ligand poses were retained for the protein structural refinements. The docking boxes are defined to include all amino acid residues within the dimensions of $25 \AA \times 25 \AA \times 25 \AA$ from the center of the original ligands; the induced-fit protein-ligand complexes are generated using the Prime software $[77,78]$. The 20 structures from the previous step were submitted to sidechain and backbone refinements. All residues with at least one atom located within $5.0 \AA$ A of each corresponding ligand pose were included in the refinement by Prime. All poses generated were then hierarchically classified, refined, and further minimized into the active site grid before being finally scored using the proprietary GlideScore function, defined as GScore $=0.065 * \mathrm{vdW}+030$ * Coul $+\mathrm{Lipo}+\mathrm{Hbond}+\mathrm{Metal}+\mathrm{BuryP}+\operatorname{RotB}+$ Site, where: vdW is the van der Waals energy term, Coul is the Coulomb energy, Lipo is a Lipophilic contact term that rewards favorable hydrophobic interactions, Hbond is an H-bonding term, Metal is a metal-binding term (where applicable), BuryP is a penalty term applied to buried polar groups, RotB is a penalty for freezing rotatable bonds, and Site is a term used to describe favorable polar interactions in the active site.

Finally, the IFD score (IFD score = 1.0 Glide_Gscore + 0.05 Prime_Energy), which accounts for both protein-ligand interaction energy and total energy of the system, was calculated and used to rank the IFD poses. The more negative was the IFDscore, the more favorable was the binding.

\section{Conclusions}

Despite the numerous efforts of the last 20 years, the therapy of HIV infection still represents a challenge, for many factors. Even today, HIV-1 PR inhibitors characterize, together with the inhibitors of reverse transcriptase, the mainstays of HIV pharmacological therapy.

If the advent of saquinavir-the first HIV-1 PR inhibitor-in 1995, symbolized a fundamental step for the treatment of HIV-infected patients, the daily and prolonged use of these agents caused many side-effects, some of which were unbearable. This is due to the capability of a lot of these drugs to interact, not only with the principal target HIV-1 PR, but also with other "secondary" targets involved in metabolic regulation and cell proliferation.

Many efforts were made along the years to select new possible inhibitors, in order to overcome the drawbacks of these class of pharmaceuticals, and in this light, computational approaches permit to dramatically reduce the time and costs of research.

In this work, we reported a new, reliable, mixed in-silico ligand/structure-based protocol that use on/off-targets, in order to select new possible leads, such as HIV-1 PR with optimal on/off-target profiles. Through our recently developed ligand-based tool available in DRUDIT (BIOTARGET finder tool), it was possible to rapidly screen and skim a large structure database (more than 38.000 compounds), selecting only those with the best activity against HIV-1 PR on-target, without a considerable affinity against the selected offtargets. The 20 best-scored molecules were further analyzed with conventionally induced fit docking protocols, in order to integrate and confirm the results obtained in the first part of the protocol. By merging the ligand and the structure-based data for the twenty selected molecules, the NSC669704 and NSC672457 molecules resulted in the best structures with optimal predicted on/off-target balance, in both ligand and structure-based studies.

The analysis of the best-docked poses of the two ligands, in complex with HIV-1 PR, showed the capability of both compounds to form interactions with the key amino acid residues within the active site, maintaining the two flap regions in a locked state over the catalytic cleft.

In summary, the proposed new in silico protocol based on on/off-targets could represent an important help in the design of new targeted agents, without unbearable promiscuous interactions. Obviously, further studies are necessary to confirm, in wet, the reliability of the protocol. 
Supplementary Materials: The following are available online at https:/ /www.mdpi.com/article/10 $.3390 /$ ijms22116070/s1.

Author Contributions: Conceptualization, A.L. and A.M.; Data curation, G.L.M. and A.B.; Investigation, A.M.; Methodology, G.L.M. and A.L.; Software, A.L.; Supervision, A.L. and A.M.; Validation, G.L.M. and A.B.; Writing-original draft, G.L.M. and A.B. All authors have read and agreed to the published version of the manuscript.

Funding: This work was in part supported by PJ_RIC_FFABR_2017_005832 Grant-University of Palermo and by the European Union 2014-2020 PON Ricerca e Innovazione grant from the Italian Ministry of Education, University, and Research, entitled "PROGEMA-Processi Green per l'Estrazione di Principi Attivi e la Depurazione di Matrici di Scarto e Non" (ARS01_00432).

Institutional Review Board Statement: Not applicable.

Informed Consent Statement: Not applicable.

Data Availability Statement: Not applicable.

Conflicts of Interest: The authors declare no conflict of interest.

\section{References}

1. Konvalinka, J.; Kräusslich, H.G.; Müller, B. Retroviral proteases and their roles in virion maturation. Virology 2015, 479-480, 403-417. [CrossRef]

2. Turner, B.G.; Summers, M.F. Structural biology of HIV. J. Mol. Biol. 1999, 285, 1-32. [CrossRef]

3. Kaplan, A.H.; Zack, J.A.; Knigge, M.; Paul, D.A.; Kempf, D.J.; Norbeck, D.W.; Swanstrom, R. Partial inhibition of the human immunodeficiency virus type 1 protease results in aberrant virus assembly and the formation of noninfectious particles. J. Virol. 1993, 67, 4050-4055. [CrossRef]

4. Rosé, J.R.; Babé, L.M.; Craik, C.S. Defining the level of human immunodeficiency virus type 1 (HIV-1) protease activity required for HIV-1 particle maturation and infectivity. J. Virol. 1995, 69, 2751-2758. [CrossRef]

5. Kohl, N.E.; Emini, E.A.; Schleif, W.A.; Davis, L.J.; Heimbach, J.C.; Dixon, R.A.; Scolnick, E.M.; Sigal, I.S. Active human immunodeficiency virus protease is required for viral infectivity. Proc. Natl. Acad. Sci. USA 1988, 85, 4686-4690. [CrossRef] [PubMed]

6. Billich, S.; Knoop, M.T.; Hansen, J.; Strop, P.; Sedlacek, J.; Mertz, R.; Moelling, K. Synthetic peptides as substrates and inhibitors of human immune deficiency virus-1 protease. J. Biol. Chem. 1988, 263, 17905-17908. [CrossRef]

7. Clavel, F.; Mammano, F. Role of Gag in HIV Resistance to Protease Inhibitors. Viruses 2010, 2, 1411-1426. [CrossRef] [PubMed]

8. Huff, J.R. HIV protease: A novel chemotherapeutic target for AIDS. J. Med. Chem. 1991, 34, 2305-2314. [CrossRef]

9. Seelmeier, S.; Schmidt, H.; Turk, V.; von der Helm, K. Human immunodeficiency virus has an aspartic-type protease that can be inhibited by pepstatin A. Proc. Natl. Acad. Sci. USA 1988, 85, 6612-6616. [CrossRef]

10. Louis, J.M.; Ishima, R.; Torchia, D.A.; Weber, I.T. HIV-1 protease: Structure, dynamics, and inhibition. Adv. Pharmacol. 2007, 55, 261-298. [CrossRef]

11. Louis, J.M.; Weber, I.T.; Tözsér, J.; Clore, G.M.; Gronenborn, A.M. HIV-1 protease: Maturation, enzyme specificity, and drug resistance. Adv. Pharmacol. 2000, 49, 111-146. [CrossRef] [PubMed]

12. Gustchina, A.; Weber, I.T. Comparative analysis of the sequences and structures of HIV-1 and HIV-2 proteases. Proteins 1991, 10, 325-339. [CrossRef]

13. Darke, P.L.; Leu, C.T.; Davis, L.J.; Heimbach, J.C.; Diehl, R.E.; Hill, W.S.; Dixon, R.A.; Sigal, I.S. Human immunodeficiency virus protease. Bacterial expression and characterization of the purified aspartic protease. J. Biol. Chem. 1989, 264, 2307-2312. [CrossRef]

14. Mous, J.; Heimer, E.P.; Le Grice, S.F. Processing protease and reverse transcriptase from human immunodeficiency virus type I polyprotein in Escherichia coli. J. Virol. 1988, 62, 1433-1436. [CrossRef]

15. Brik, A.; Wong, C.H. HIV-1 protease: Mechanism and drug discovery. Org. Biomol. Chem. 2003, 1, 5-14. [CrossRef] [PubMed]

16. Mager, P.P. The active site of HIV-1 protease. Med. Res. Rev. 2001, 21, 348-353. [CrossRef]

17. Kovalevsky, A.Y.; Chumanevich, A.A.; Liu, F.; Louis, J.M.; Weber, I.T. Caught in the Act: The 1.5 A resolution crystal structures of the HIV-1 protease and the I54V mutant reveal a tetrahedral reaction intermediate. Biochemistry 2007, 46, 14854-14864. [CrossRef]

18. Kumar, M.; Prashar, V.; Mahale, S.; Hosur, M.V. Observation of a tetrahedral reaction intermediate in the HIV-1 protease-substrate complex. Biochem. J. 2005, 389, 365-371. [CrossRef]

19. Suguna, K.; Padlan, E.A.; Smith, C.W.; Carlson, W.D.; Davies, D.R. Binding of a reduced peptide inhibitor to the aspartic proteinase from Rhizopus chinensis: Implications for a mechanism of action. Proc. Natl. Acad. Sci. USA 1987, 84, 7009-7013. [CrossRef]

20. Lapatto, R.; Blundell, T.; Hemmings, A.; Overington, J.; Wilderspin, A.; Wood, S.; Merson, J.R.; Whittle, P.J.; Danley, D.E.; Geoghegan, K.F. X-ray analysis of HIV-1 proteinase at 2.7 A resolution confirms structural homology among retroviral enzymes. Nature 1989, 342, 299-302. [CrossRef] 
21. Cígler, P.; Kozísek, M.; Rezácová, P.; Brynda, J.; Otwinowski, Z.; Pokorná, J.; Plesek, J.; Grüner, B.; Dolecková-Maresová, L.; Mása, M.; et al. From nonpeptide toward noncarbon protease inhibitors: Metallacarboranes as specific and potent inhibitors of HIV protease. Proc. Natl. Acad. Sci. USA 2005, 102, 15394-15399. [CrossRef]

22. Kožíšek, M.; Lepšík, M.; Grantz Šašková, K.; Brynda, J.; Konvalinka, J.; Rezáčová, P. Thermodynamic and structural analysis of HIV protease resistance to darunavir-analysis of heavily mutated patient-derived HIV-1 proteases. FEBS J. 2014, 281, $1834-1847$. [CrossRef] [PubMed]

23. Pettit, S.C.; Henderson, G.J.; Schiffer, C.A.; Swanstrom, R. Replacement of the P1 amino acid of human immunodeficiency virus type 1 Gag processing sites can inhibit or enhance the rate of cleavage by the viral protease. J. Virol. 2002, 76, 10226-10233. [CrossRef] [PubMed]

24. Weber, I.T.; Agniswamy, J. HIV-1 Protease: Structural Perspectives on Drug Resistance. Viruses 2009, 1, 1110-1136. [CrossRef]

25. Voshavar, C. Protease Inhibitors for the Treatment of HIV/AIDS: Recent Advances and Future Challenges. Curr. Top. Med. Chem. 2019, 19, 1571-1598. [CrossRef] [PubMed]

26. Tie, Y.; Boross, P.I.; Wang, Y.F.; Gaddis, L.; Hussain, A.K.; Leshchenko, S.; Ghosh, A.K.; Louis, J.M.; Harrison, R.W.; Weber, I.T. High resolution crystal structures of HIV-1 protease with a potent non-peptide inhibitor (UIC-94017) active against multi-drug-resistant clinical strains. J. Mol. Biol. 2004, 338, 341-352. [CrossRef]

27. Roberts, N.A.; Martin, J.A.; Kinchington, D.; Broadhurst, A.V.; Craig, J.C.; Duncan, I.B.; Galpin, S.A.; Handa, B.K.; Kay, J.; Kröhn, A. Rational design of peptide-based HIV proteinase inhibitors. Science 1990, 248, 358-361. [CrossRef] [PubMed]

28. Adamson, C.S. Protease-Mediated Maturation of HIV: Inhibitors of Protease and the Maturation Process. Mol. Biol. Int. 2012 2012, 604261. [CrossRef]

29. Ghosh, A.K.; Osswald, H.L.; Prato, G. Recent Progress in the Development of HIV-1 Protease Inhibitors for the Treatment of HIV / AIDS. J. Med. Chem. 2016, 59, 5172-5208. [CrossRef]

30. Lv, Z.; Chu, Y.; Wang, Y. HIV protease inhibitors: A review of molecular selectivity and toxicity. HIV AIDS 2015, 7, 95-104. [CrossRef]

31. Lauria, A.; Bonsignore, R.; Bartolotta, R.; Perricone, U.; Martorana, A.; Gentile, C. Drugs Polypharmacology by In Silico Methods: New Opportunities in Drug Discovery. Curr. Pharm. Des. 2016, 22, 3073-3081. [CrossRef]

32. Anighoro, A.; Bajorath, J.; Rastelli, G. Polypharmacology: Challenges and opportunities in drug discovery. J. Med. Chem. 2014, 57, 7874-7887. [CrossRef] [PubMed]

33. Nolan, D. Metabolic complications associated with HIV protease inhibitor therapy. Drugs 2003, 63, 2555-2574. [CrossRef] [PubMed]

34. Nascimento, A.L.C.S.; Fernandes, R.P.; Quijia, C.; Araujo, V.H.S.; Pereira, J.; Garcia, J.S.; Trevisan, M.G.; Chorilli, M. Pharmacokinetic Parameters of HIV-1 Protease Inhibitors. Chem. Med. Chem. 2020, 15, 1018-1029. [CrossRef] [PubMed]

35. Xie, L.; Evangelidis, T.; Bourne, P.E. Drug discovery using chemical systems biology: Weak inhibition of multiple kinases may contribute to the anti-cancer effect of nelfinavir. PLoS Comput. Biol. 2011, 7. [CrossRef]

36. Gills, J.J.; Lopiccolo, J.; Tsurutani, J.; Shoemaker, R.H.; Best, C.J.; Abu-Asab, M.S.; Borojerdi, J.; Warfel, N.A.; Gardner, E.R.; Danish, M.; et al. Nelfinavir, A lead HIV protease inhibitor, is a broad-spectrum, anticancer agent that induces endoplasmic reticulum stress, autophagy, and apoptosis in vitro and in vivo. Clin. Cancer Res. 2007, 13, 5183-5194. [CrossRef]

37. Koethe, J.R. Adipose Tissue in HIV Infection. Compr. Physiol. 2017, 7, 1339-1357. [CrossRef] [PubMed]

38. Ben-Romano, R.; Rudich, A.; Tirosh, A.; Potashnik, R.; Sasaoka, T.; Riesenberg, K.; Schlaeffer, F.; Bashan, N. Nelfinavir-induced insulin resistance is associated with impaired plasma membrane recruitment of the PI 3-kinase effectors Akt/PKB and PKC-zeta. Diabetologia 2004, 47, 1107-1117. [CrossRef] [PubMed]

39. Gupta, A.K.; Cerniglia, G.J.; Mick, R.; McKenna, W.G.; Muschel, R.J. HIV protease inhibitors block Akt signaling and radiosensitize tumor cells both in vitro and in vivo. Cancer Res. 2005, 65, 8256-8265. [CrossRef] [PubMed]

40. Hruz, P.W. HIV protease inhibitors and insulin resistance: Lessons from in-vitro, rodent and healthy human volunteer models. Curr. Opin. HIV AIDS 2008, 3, 660-665. [CrossRef]

41. Anuurad, E.; Bremer, A.; Berglund, L. HIV protease inhibitors and obesity. Curr. Opin. Endocrinol. Diabetes Obes. 2010, 17, 478-485 [CrossRef] [PubMed]

42. Subeha, M.R.; Telleria, C.M. The Anti-Cancer Properties of the HIV Protease Inhibitor Nelfinavir. Cancers 2020, 12, 3734. [CrossRef]

43. Simon, V.; Ho, D.D.; Abdool Karim, Q. HIV/AIDS epidemiology, pathogenesis, prevention, and treatment. Lancet 2006, 368, 489-504. [CrossRef]

44. Murata, H.; Hruz, P.W.; Mueckler, M. The mechanism of insulin resistance caused by HIV protease inhibitor therapy. J. Biol. Chem. 2000, 275, 20251-20254. [CrossRef]

45. Chaudhari, R.; Tan, Z.; Huang, B.; Zhang, S. Computational polypharmacology: A new paradigm for drug discovery. Expert Opin. Drug Discov. 2017, 12, 279-291. [CrossRef] [PubMed]

46. Zloh, M.; Kirton, S.B. The benefits of in silico modeling to identify possible small-molecule drugs and their off-target interactions. Future Med. Chem. 2018, 10, 423-432. [CrossRef] [PubMed]

47. Lavecchia, A.; Cerchia, C. In silico methods to address polypharmacology: Current status, applications and future perspectives. Drug Discov. Today 2016, 21, 288-298. [CrossRef]

48. Brüning, A. Targeting the off-targets: A computational bioinformatics approach to understanding the polypharmacology of nelfinavir. Expert Rev. Clin. Pharmacol. 2011, 4, 571-573. [CrossRef] 
49. Lauria, A.; Mannino, S.; Gentile, C.; Mannino, G.; Martorana, A.; Peri, D. DRUDIT: Web-based DRUgs DIscovery Tools to design small molecules as modulators of biological targets. Bioinformatics 2020, 36, 1562-1569. [CrossRef]

50. Liu, T.; Lin, Y.; Wen, X.; Jorissen, R.N.; Gilson, M.K. BindingDB: A web-accessible database of experimentally determined protein-ligand binding affinities. Nucleic Acids Res. 2007, 35, D198-D201. [CrossRef]

51. Lauria, A.; Tutone, M.; Almerico, A.M. Virtual lock-and-key approach: The in silico revival of Fischer model by means of molecular descriptors. Eur. J. Med. Chem. 2011, 46, 4274-4280. [CrossRef]

52. Covell, D.G.; Huang, R.; Wallqvist, A. Anticancer medicines in development: Assessment of bioactivity profiles within the National Cancer Institute anticancer screening data. Mol. Cancer Ther. 2007, 6, 2261-2270. [CrossRef] [PubMed]

53. Shoemaker, R.H. The NCI60 human tumour cell line anticancer drug screen. Nat. Rev. Cancer 2006, 6, 813-823. [CrossRef]

54. Martorana, A.; Perricone, U.; Lauria, A. The Repurposing of Old Drugs or Unsuccessful Lead Compounds by in Silico Approaches: New Advances and Perspectives. Curr. Top. Med. Chem. 2016, 16, 2088-2106. [CrossRef]

55. Koltai, T. Nelfinavir and other protease inhibitors in cancer: Mechanisms involved in anticancer activity. F1000Research 2015, 4, 9. [CrossRef]

56. Kumar, A.; Zhang, K.Y. Hierarchical virtual screening approaches in small molecule drug discovery. Methods 2015, 71, 26-37. [CrossRef] [PubMed]

57. Lam, P.Y.; Jadhav, P.K.; Eyermann, C.J.; Hodge, C.N.; Ru, Y.; Bacheler, L.T.; Meek, J.L.; Otto, M.J.; Rayner, M.M.; Wong, Y.N. Rational design of potent, bioavailable, nonpeptide cyclic ureas as HIV protease inhibitors. Science 1994, 263, 380-384. [CrossRef] [PubMed]

58. Huang, W.S.; Liu, S.; Zou, D.; Thomas, M.; Wang, Y.; Zhou, T.; Romero, J.; Kohlmann, A.; Li, F.; Qi, J.; et al. Discovery of Brigatinib (AP26113), a Phosphine Oxide-Containing, Potent, Orally Active Inhibitor of Anaplastic Lymphoma Kinase. J. Med. Chem. 2016, 59, 4948-4964. [CrossRef]

59. Sogabe, S.; Kawakita, Y.; Igaki, S.; Iwata, H.; Miki, H.; Cary, D.R.; Takagi, T.; Takagi, S.; Ohta, Y.; Ishikawa, T. Structure-Based Approach for the Discovery of Pyrrolo[3,2-d]pyrimidine-Based EGFR T790M/L858R Mutant Inhibitors. ACS Med. Chem. Lett. 2013, 4, 201-205. [CrossRef]

60. Degorce, S.L.; Boyd, S.; Curwen, J.O.; Ducray, R.; Halsall, C.T.; Jones, C.D.; Lach, F.; Lenz, E.M.; Pass, M.; Pass, S.; et al. Discovery of a Potent, Selective, Orally Bioavailable, and Efficacious Novel 2-(Pyrazol-4-ylamino)-pyrimidine Inhibitor of the Insulin-like Growth Factor-1 Receptor (IGF-1R). J. Med. Chem. 2016, 59, 4859-4866. [CrossRef]

61. Berman, H.M.; Westbrook, J.; Feng, Z.; Gilliland, G.; Bhat, T.N.; Weissig, H.; Shindyalov, I.N.; Bourne, P.E. The Protein Data Bank. Nucleic Acids Res. 2000, 28, 235-242. [CrossRef] [PubMed]

62. Wei, Y.; Li, J.; Chen, Z.; Wang, F.; Huang, W.; Hong, Z.; Lin, J. Multistage virtual screening and identification of novel HIV-1 protease inhibitors by integrating SVM, shape, pharmacophore and docking methods. Eur. J. Med. Chem. 2015, 101, 409-418. [CrossRef] [PubMed]

63. Schrödinger Release 2017-2, LigPrep; Schrödinger, LLC: New York, NY, USA, 2017.

64. Schrödinger Release 2017-2, Schrödinger Suite 2017-2 Protein Preparation Wizard; Epik, Schrödinger, LLC: New York, NY, USA, 2017.

65. Banks, J.L.; Beard, H.S.; Cao, Y.; Cho, A.E.; Damm, W.; Farid, R.; Felts, A.K.; Halgren, T.A.; Mainz, D.T.; Maple, J.R.; et al. Integrated Modeling Program, Applied Chemical Theory (IMPACT). J. Comput. Chem. 2005, 26, 1752-1780. [CrossRef]

66. RCSB PDB. Available online: www.rcsb.org (accessed on 1 May 2021).

67. Sastry, G.M.; Adzhigirey, M.; Day, T.; Annabhimoju, R.; Sherman, W. Protein and ligand preparation: Parameters, protocols, and influence on virtual screening enrichments. J. Comput. Aided Mol. Des. 2013, 27, 221-234. [CrossRef]

68. Halgren, T.A.; Murphy, R.B.; Friesner, R.A.; Beard, H.S.; Frye, L.L.; Pollard, W.T.; Banks, J.L. Glide: A new approach for rapid, accurate docking and scoring. 2. Enrichment factors in database screening. J. Med. Chem. 2004, 47, 1750-1759. [CrossRef]

69. Friesner, R.A.; Murphy, R.B.; Repasky, M.P.; Frye, L.L.; Greenwood, J.R.; Halgren, T.A.; Sanschagrin, P.C.; Mainz, D.T. Extra precision glide: Docking and scoring incorporating a model of hydrophobic enclosure for protein-ligand complexes. J. Med. Chem. 2006, 49, 6177-6196. [CrossRef] [PubMed]

70. Friesner, R.A.; Banks, J.L.; Murphy, R.B.; Halgren, T.A.; Klicic, J.J.; Mainz, D.T.; Repasky, M.P.; Knoll, E.H.; Shelley, M.; Perry, J.K.; et al. Glide: A new approach for rapid, accurate docking and scoring. 1. Method and assessment of docking accuracy. J. Med. Chem. 2004, 47, 1739-1749. [CrossRef]

71. Sherman, W.; Beard, H.S.; Farid, R. Use of an induced fit receptor structure in virtual screening. Chem. Biol. Drug Des. 2006, 67, 83-84. [CrossRef]

72. Sherman, W.; Day, T.; Jacobson, M.P.; Friesner, R.A.; Farid, R. Novel procedure for modeling ligand/receptor induced fit effects. J. Med. Chem. 2006, 49, 534-553. [CrossRef]

73. Maestro, version 9.3; Schrödinger, LLC: New York, NY, USA, 2012.

74. Zhong, H.; Tran, L.M.; Stang, J.L. Induced-fit docking studies of the active and inactive states of protein tyrosine kinases. J. Mol. Graph. Model. 2009, 28, 336-346. [CrossRef] [PubMed]

75. Wang, H.; Aslanian, R.; Madison, V.S. Induced-fit docking of mometasone furoate and further evidence for glucocorticoid receptor 17alpha pocket flexibility. J. Mol. Graph. Model. 2008, 27, 512-521. [CrossRef] [PubMed]

76. Luo, H.-J.; Wang, J.-Z.; Deng, W.-Q.; Zou, K. Induced-fit docking and binding free energy calculation on furostanol saponins from Tupistra chinensis as epidermal growth factor receptor inhibitors. Med. Chem. Res. 2013, 22, 4970-4979. [CrossRef] 
77. Jacobson, M.P.; Pincus, D.L.; Rapp, C.S.; Day, T.J.; Honig, B.; Shaw, D.E.; Friesner, R.A. A hierarchical approach to all-atom protein loop prediction. Proteins 2004, 55, 351-367. [CrossRef] [PubMed]

78. Jacobson, M.P.; Friesner, R.A.; Xiang, Z.; Honig, B. On the role of the crystal environment in determining protein side-chain conformations. J. Mol. Biol. 2002, 320, 597-608. [CrossRef] 